\title{
Role of Diffuse Tensor Imaging in Predicting Outcomes of Decompressive Surgery in Degenerative Cervical Myelopathy-A Prospective Analysis
}

\author{
Neeraj Sharma ${ }^{1}$ Rajesh Alugolu ${ }^{1}$ Dinesh Gangapatnam ${ }^{1} \quad$ Mudumba Vijaya Saradhi ${ }^{1}$ \\ ${ }^{1}$ Department of Neurosurgery, Nizam's Institute of Medical Sciences, \\ Hyderabad, Telangana, India \\ Indian J Neurosurg 2023;12:30-36. \\ Address for correspondence Rajesh Alugolu, MBBS, MS, MCh, \\ Department of Neurosurgery, Nizam's Institute of Medical Sciences, \\ Punjagutta, Hyderabad, Telangana, 500082, India \\ (e-mail: drarajesh1306@gmail.com).
}

\begin{abstract}
Background Cervical spondylotic myelopathy is a common degenerative disorder of the cervical spine. Assessing the severity of the disease objectively remains a challenge. Advances in magnetic resonance imaging (MRI), especially diffusion tensor imaging (DTI), elucidate the damaged or compressed fiber tracts in the cord. This study is our endeavor to correlate the relationship between clinical features, radiological features with special reference to DTI, and surgical outcome in patients with degenerative cervical myelopathy.

Methods All consecutive patients of cervical spondylotic myelopathy and cord intensity changes in MRI, admitted and treated in the department of neurosurgery during the period of 2016 to 2018, were included and evaluated clinically and radiologically. The clinical evaluation included motor assessment scale (MAS), 30 meters walking, and hand grip. Radiological investigations included additional DTI in 3T MRI and clinical outcome was measured postoperatively after 12 months by modified Japanese Orthopedic Association (mJOA) recovery ratio and MAS scores.

Results The patients age ranged from 30 to 80 years and the mean age of the study population was $55.95 \pm 10$ years. Patients with fractional anisotropy (FA) $<0.5$ had higher grade of Nurick, that is, grade 5 in $4.3 \%$, grade 4 in $65.2 \%$, and grade 3 in $27.1 \%$ compared with grade 5 in $0 \%$, grade 4 in $23.5 \%$, and grade 3 in $47.1 \%$ in FA $>0.5$. Mean $\mathrm{mJOA}$ recovery ratio in the group $\mathrm{FA}>0.5$ was 57.32 whereas it was 38.78 in $\mathrm{FA}<0.5$. Conclusion DTI serves as a potential biomarker for predicting the surgical outcome in

Keywords

- myelopathy

- functional

- anisotropy degenerative cervical myelopathy cases and thereby making the surgical decision precise. FA can be a potential quantitative tool to predict the functional outcome following decompressive surgery for degenerative cervical myelopathy conditions, in particular lower FA values carries poor prognosis.
\end{abstract}

article published online December 15, 2021
DOI https://doi.org/ $10.1055 / \mathrm{s}-0041-1727421$ ISSN 2277-954X.

\footnotetext{
(c) 2021. Neurological Surgeons' Society of India. All rights reserved. This is an open access article published by Thieme under the terms of the Creative Commons Attribution-NonDerivative-NonCommercial-License, permitting copying and reproduction so long as the original work is given appropriate credit. Contents may not be used for commercial purposes, or adapted, remixed, transformed or built upon. (https://creativecommons.org/ licenses/by-nc-nd/4.0/)

Thieme Medical and Scientific Publishers Pvt. Ltd., A-12, 2nd Floor, Sector 2, Noida-201301 UP, India
} 


\section{Introduction}

Degenerative cervical myelopathy is a common disorder of the cervical spine and is the most common cause of cervical spinal cord dysfunction. ${ }^{1}$ It is a progressive degenerative spine abnormality, causing cervical spinal cord damage. ${ }^{2}$ It affects almost every person over 40 years, earlier or later. ${ }^{3}$ Pathogenesis of degenerative cervical myelopathy is composed of static and dynamic factors. ${ }^{4}$ Assessing the severity of the disease, objectively, remains a challenge.

Magnetic resonance imaging (MRI) of the cervical spine may show high signal intensity on $\mathrm{T} 2 \mathrm{~W}$ sequence at the most compressed part. ${ }^{5-8}$ However, the true prognostication is not feasible as the anatomical imaging is unable to quantify the damage as to temporary or permanent and its effect especially after surgical decompression.

Advances in MRI, especially diffusion tensor imaging (DTI), elucidate the damaged or compressed fiber tracts in the cord. ${ }^{9-12}$ This study is our endeavor to correlate the relationship between clinical features, radiological features with special reference to DTI, and surgical outcome in patients with degenerative cervical myelopathy.

\section{Materials and Methods}

The present prospective study included all degenerative cervical myelopathy patients who attended the Department of Neurosurgery, Nizam's Institute of Medical Sciences, Hyderabad, Telangana, India, from September 2016 to October 2018 requiring surgical intervention. A total of 60 patients who met the defined inclusion criteria were included; however, those who deteriorated in the postoperative period $(n=20)$ were excluded from the study.

\section{Inclusion Criteria}

All symptomatic cervical myelopathy patients between 18 and 80 years with radiological changes in sagittal T2W imaging, with prolapsed intervertebral discs, ossified posterior longitudinal ligament, and ossified ligamentum flavum in whom the neurological level corroborated with the imaging findings, were included in the surgical cohort.

\section{Exclusion Criteria}

Patients with cervical trauma including acute or chronic injuries, spinal tumors, previous cranial surgeries, and those who deteriorated neurologically in the postoperative period ( $n=20$ ) were excluded from the study.

All patients with grade 2 and 3 myelomalacia changes on MRI requiring surgical intervention were evaluated. Clinical workup included: assessment of tone by Modified Ashworth score, hand grip force, Nurick grading, and modified Japanese Orthopedic Association (mJOA) score in the preoperative period and 6 months following surgery.

Radiological workup included assessment of signal intensity changes on T1W and T2W sequences of cervical spine MRI in sagittal planes. MRI contrast imaging did not add up to any added advantage for diagnosis and outcome of these patients. DTI was performed in the preoperative period in a 3T Siemens-
MAGNETOM Skyra (Germany) machine in all these cases with the following parameters: $\mathrm{TR}=2,790 \mathrm{~ms}, \mathrm{TE}=83 \mathrm{~ms}$, $\mathrm{FOV}=220 \mathrm{~mm} \times 110 \mathrm{~mm}$, matrix $=160 \times 160$ pixels, slice thickness $=3 \mathrm{~mm}$, gap $=0.3 \mathrm{~mm}, b=0, b=800 \mathrm{~s} / \mathrm{mm}^{2}$, number of slices $=15$, approximate time for scan was 4 minutes and 15 seconds. Fractional anisotropy (FA) values were obtained at the most stenosed level and at the relatively noncompressed cranial level (C1-C2).

\section{Statistical Analysis}

The continuous data are expressed as mean with standard deviation, while categorical data as frequency of occurrence and percentages. Data was analyzed using SPSS version 17.0 (SPSS, Inc., Chicago, Illinois, United States). Means and standard deviations were computed for continuous variables. Comparisons of categorical variables were performed using chi-square test and a $p$-value of $<0.05$ was considered significant. Logistic regression was used when multivariate analysis was required.

\section{Results}

\section{Demography}

The mean age of the study group was 55.95 years (range $30-80$ years). Apart from signs of myelopathy, $42.5 \%(n=17)$ patients had radiculopathy, 30\% $(n=12)$ had sphincter disturbances, and $70 \%(n=28)$ had breathlessness. Single-level disease was noted in 16 patients (40\%), 10 patients (25\%) had two-level disease, 9 (22.5\%) had three-level disease, and 5 (12.5\%) patients had four-level disease (-Table 1). In 24 patients

Table 1 Demographics

\begin{tabular}{|c|c|c|}
\hline & & $N$ \\
\hline Age $(y)$ & $\begin{array}{l}41-50 \\
51-60 \\
61-70\end{array}$ & $\begin{array}{l}15 \\
70 \\
15\end{array}$ \\
\hline Gender & $\begin{array}{l}\text { Male } \\
\text { Female }\end{array}$ & $\begin{array}{l}35 \\
05\end{array}$ \\
\hline $\begin{array}{l}\text { Presenting } \\
\text { symptom }\end{array}$ & $\begin{array}{l}\text { Radiculopathy } \\
\text { Sphincter disturbances } \\
\text { Respiratory difficulty }\end{array}$ & $\begin{array}{l}17 \\
12 \\
28\end{array}$ \\
\hline Levels of disease & $\begin{array}{l}1 \text { level } \\
2 \text { levels } \\
3 \text { levels } \\
>4 \text { levels }\end{array}$ & $\begin{array}{l}16 \\
10 \\
9 \\
5\end{array}$ \\
\hline \multicolumn{3}{|l|}{$\begin{array}{l}\text { Disease causing } \\
\text { myelopathy }\end{array}$} \\
\hline OPLL & & $20(50 \%)$ \\
\hline PIVD & & $20(50 \%)$ \\
\hline \multicolumn{3}{|l|}{ MRI changes } \\
\hline Grade I & No signal change & $n=0$ \\
\hline Grade II & Signal change only on $\mathrm{T} 2 \mathrm{~W}$ & $n=36$ \\
\hline Grade III & $\begin{array}{l}\text { Signal change on T1W and } \\
\text { T2W }\end{array}$ & $n=4$ \\
\hline
\end{tabular}

Abbreviations: MRI, magnetic resonance imaging; OPLL, ossification of the posterior longitudinal ligament; PIVD, prolapsed intervertebral disc. 


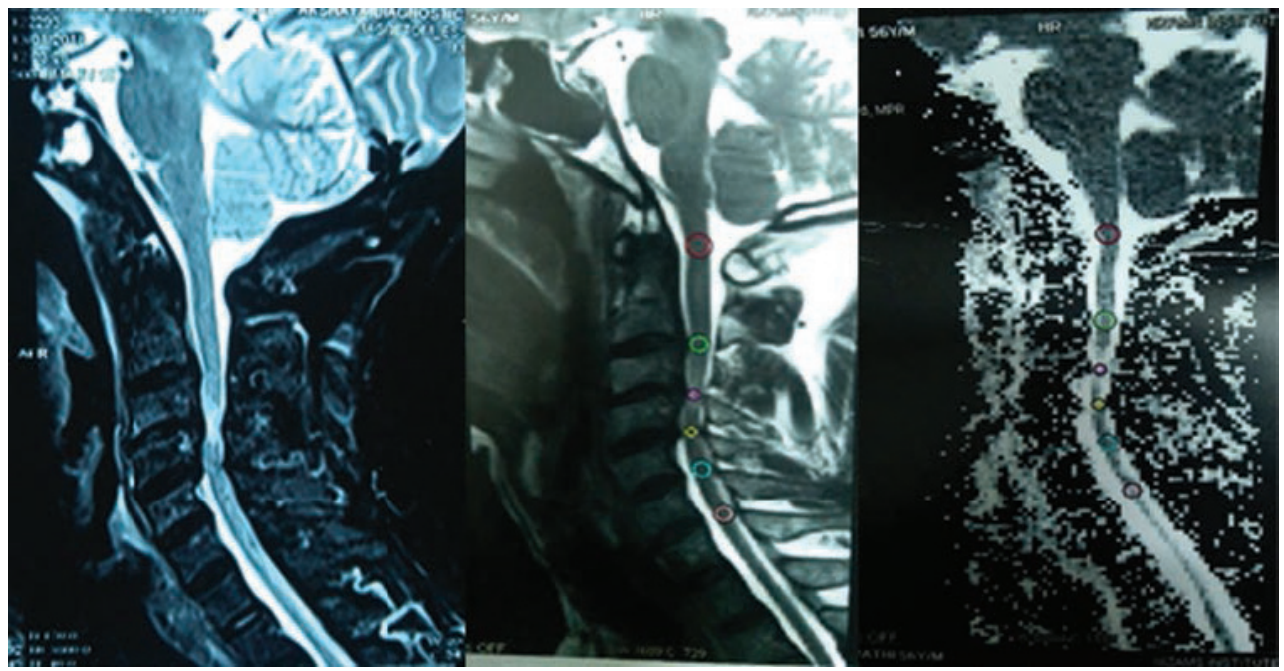

Fig. 1 A case having cervical ossification of the posterior longitudinal ligament (OPLL) with intense hyperintensity at C3-C4 level on T2 sequence, for which diffusion tensor imaging (DTI) has been done and region of interest (ROI) has been marked at various levels and fractional anisotropy (FA) mapping has been done.

surgery was done through posterior approach and anterior approach was followed in 16 patients, decision made on the basis of k-line drawn on plain radiograph.

\section{Radiological Parameters}

On MRI sagittal planes, signal intensity changes were graded as grade II (signal intensity changes on only T2) and grade III (both on T2, T1). Grade II MRI changes were present in both on T2 and T1 (-Fig. 1), 36 patients (90\%), and 4 patients (10\%) had grade III changes in the spinal cord ( - Table 1 ). FA values were measured at the most compressed levels and at relatively noncompressed $\mathrm{C} 1-\mathrm{C} 2$ levels acting as a reference standard in all the patients. The mean FA value at $\mathrm{C} 1-\mathrm{C} 2$ ranged from 0.56 to 0.85 . FA values ( - Fig. 1$)$ at the diseased or most compressed segment was observed to be in the range of 0.29 to 0.76 . We took FA 0.5 as the arbitrary limit and divided patients into two groups with FA $\leq 0.5$ (23 patients) and FA $>0.5$ (17 patients) and compared the results (-Table $\mathbf{2}$ ).

\section{Clinical Parameters}

Tone was assessed by Modified Ashworth Scale. Preoperatively, motor assessment scale (MAS) ranged from 1 to 4 with mean of
Table 2 Fractional anisotropy values

\begin{tabular}{|l|l|l|}
\hline & Mean & SD \\
\hline FA at C1-C2 & 0.698 & 0.072 \\
\hline FA at diseased level & 0.473 & 0.099 \\
\hline
\end{tabular}

Abbreviations: FA, fractional anisotropy; SD, standard deviation.

1.72. Postoperative MAS ranged from 0 to 2 and mean decreased in the postoperative period to 0.82 , which was statistically significant $(p<0.001)$. Hand grip force $(\mathrm{kg})$ was assessed in both the hands by manual dynamometer and preoperatively it ranged from 28 to $80 \mathrm{~kg}$ in the right hand and 20 to $75 \mathrm{~kg}$ in the left hand. Postoperatively, grip ranged from 40 to $110 \mathrm{~kg}$ in both the hands and mean values were $75.75 \%$ in the right hand and $72.75 \%$ in the left hand and the improvement was statistically significant $(p<0.001)$. Respiratory status was assessed by single ball incentive spirometer, preoperative values ranged from 300 to $900 \mathrm{~mL}$, mean volume was $610 \mathrm{~mL}$ and the postoperative values ranged from 600 to $1,200 \mathrm{~mL}$, mean volume was $901 \mathrm{~mL}$, the decrease is statistically significant $(p<0.001)$ ( - Table 3 ). Patients were subjected to $30 \mathrm{~m}$ walk and the time taken to

Table 3 Clinical parameters compared pre- and postoperatively

\begin{tabular}{|l|l|l|l|l|l|}
\hline & $\begin{array}{l}\text { Preoperative } \\
\text { range }\end{array}$ & Mean & $\begin{array}{l}\text { Postoperative } \\
\text { range }\end{array}$ & Mean & $p$-Value \\
\hline MAS score & $1-4$ & 1.72 & $0-2$ & 0.82 & $<0.001$ \\
\hline Incentive spirometry & $300-900 \mathrm{~mL}$ & $610 \mathrm{~mL}$ & $600-1,200 \mathrm{~mL}$ & $901 \mathrm{~mL}$ & $<0.001$ \\
\hline Hand grip & Right & Right & $\begin{array}{l}\text { Right } \\
40-110 \mathrm{~kg} \\
\text { Left } \\
40-110 \mathrm{~kg}\end{array}$ & $\begin{array}{l}\text { Right } \\
75.75 \mathrm{~kg} \\
\text { Left } \\
72.75 \mathrm{~kg}\end{array}$ & $<0.001$ \\
& Left & $\begin{array}{l}55.75 \mathrm{~kg} \\
\text { Left }\end{array}$ & $54.50 \mathrm{~kg}$ & $40 \mathrm{~kg}$ &
\end{tabular}

Abbreviation: MAS, motor assessment scale.

Note: $p$-Value was calculated using paired $t$-test. 
completion (seconds) was recorded. Preoperatively, mean time was 77.85 seconds and the mean time in the postoperative period was 71.88 seconds and the improvement was not statistically significant $(p=0.56)$.

\section{Discussion}

Management of degenerative cervical myelopathy is challenging because of multifactorial pathogenesis and variety of surgical approaches. Although imaging modalities like conventional MRI reveal the presence of signal intensity changes in T1W and T2W sequences which reflect cord damage, prognostication of the pathology and outcome by this is clearly uncertain. DTI parameters are more sensitive to detect early myelopathic changes much before its appearance on T2 sequence of conventional MRI. ${ }^{9,13,14}$ DTI can quantify the water molecule size and its direction of diffusivity which denotes the axonal fiber integrity in the cord. FA is the most commonly used quantitative tool for the dispersion of diffusion tensor indices. ${ }^{12,15,16}$ An attempt has been made to formulate a comprehensive prognostication and quantify myelomalacia by conventional MRI and DTI.

\section{Demography}

\section{Correlation between Age and Surgical Outcome}

Degenerative cervical myelopathy is the most commonly acquired cause of spinal cord dysfunction among those aged over 55 years according to Crandall and Batzdorf. ${ }^{17}$ In the Naderi et al $^{18}$ study of 27 patients with cervical spondylotic myelopathy (CSM) showed better neurological improvement in patients younger than 60 years. Holly and colleagues ${ }^{19}$ in his study confirmed age of the patient as one of the important prognostic factors. Fujiwara et $\mathrm{al}^{20}$ in his study of 50 patients with cervical myelopathy, observed that there is negative correlation between advanced age at the time of surgery with recovery rate. In our study patients whose age was less than 40 years had better $\mathrm{mJOA}$ recovery ratios ( - Table 4 ).

Table 4 Review of literature stating role of MRI in cervical myelopathy and comparison with the present study

\begin{tabular}{|c|c|c|c|c|c|}
\hline Literature & $\begin{array}{l}\text { No. of } \\
\text { patients }\end{array}$ & Correlation to age & $\begin{array}{l}\text { Correlation with no. } \\
\text { levels }\end{array}$ & Radiological findings & $\begin{array}{l}\text { Correlation with } \\
\text { FA values }\end{array}$ \\
\hline $\begin{array}{l}\text { Crandall and } \\
\text { Batzdorf }\end{array}$ & $n=62$ & $\begin{array}{l}\text { Cervical myelopathy is } \\
\text { most common after } 55 \\
\text { years }\end{array}$ & $\begin{array}{l}\text { Two level involvement is } \\
\text { most common }\end{array}$ & & \\
\hline Fujiwara et al & $n=50$ & $\begin{array}{l}\text { Negative correlation } \\
\text { between advanced age } \\
\text { at the time of surgery } \\
\text { and outcome }\end{array}$ & $\begin{array}{l}\text { Better outcome in one } \\
\text { or two level disease }\end{array}$ & & \\
\hline $\mathrm{Yu}$ & $n=248$ & & $\begin{array}{l}\text { Decrease in mean } \\
\text { preoperative mJOA and } \\
\text { NDI with increase in } \\
\text { disease level }\end{array}$ & & \\
\hline Takahashi & $n=99$ & & & $\begin{array}{l}\text { T2W signal changes had } \\
\text { poor outcome than with } \\
\text { no changes on MRI }\end{array}$ & \\
\hline Uchida et al & $n=148$ & & & $\begin{array}{l}\text { T1W change is the } \\
\text { strongest contributor } \\
\text { for outcome. } \beta \text { - } \\
\text { coefficient } 0.256\end{array}$ & \\
\hline $\begin{array}{l}\text { Chaitanya } \\
\text { Baban }\end{array}$ & $n=46$ & & & $\begin{array}{l}\text { Sharp and focal changes } \\
\text { on T2W had poor mJOA } \\
1 \text { year postoperatively }\end{array}$ & \\
\hline Vedantam et al & $n=44$ & & & & $\begin{array}{l}\mathrm{FA}<0.55 \text { had } \\
\text { low } 12 \text {-month } \\
\text { postoperative } \\
\text { mJOA values }\end{array}$ \\
\hline Present study & $n=40$ & $\begin{array}{l}\text { Better mean } \mathrm{mJOA} \\
\text { recovery rate in }< \\
40 \text { years }(p=0.222)\end{array}$ & $\begin{array}{l}\text { With increase in level, } \\
\text { there is decrease in } \\
\text { mJOA, FIM and increase } \\
\text { in NDI, Nurick grade }\end{array}$ & $\begin{array}{l}\text { Grade II - low Nurick } \\
\text { grade, low NDI, high } \\
\text { mJOA scores } \\
\text { Grade III-high Nurick } \\
\text { grade, high NDI, low } \\
\text { mJOA scores }(p<0.05)\end{array}$ & $\begin{array}{l}\mathrm{FA}<0.5 \text { has poor } \\
\mathrm{mJOA} \text { recovery } \\
\text { rates. } p=0.04\end{array}$ \\
\hline
\end{tabular}

Abbreviations: FA, fractional anisotropy; FIM, Functional Independence Measure; mJOA, modified Japanese Orthopedic Association; MRI, magnetic resonance imaging; NDI, Neck Disability Index. 
Role of Diffuse Tensor Imaging in Predicting Outcomes of Decompressive Surgery in Degenerative Cervical

Table 5 Correlation between number of levels and preop mJOA, Nurick, and FIM

\begin{tabular}{|c|c|c|c|c|c|}
\hline Parameter & No. of levels & Mean & SD & $f$-Value & $p$-Value \\
\hline \multirow[t]{4}{*}{$\mathrm{mJOA}$} & One level & 10.94 & 2.98 & \multirow[t]{4}{*}{0.337} & \multirow[t]{4}{*}{0.799} \\
\hline & Two level & 10.60 & 2.63 & & \\
\hline & Three level & 10.00 & 4.18 & & \\
\hline & Four level & 9.60 & 0.55 & & \\
\hline \multirow[t]{4}{*}{ Nurick } & One level & 2.81 & 0.75 & \multirow[t]{4}{*}{2.59} & \multirow[t]{4}{*}{0.068} \\
\hline & Two level & 3.10 & 1.45 & & \\
\hline & Three level & 3.67 & 1.00 & & \\
\hline & Four level & 4.00 & 0.00 & & \\
\hline \multirow[t]{4}{*}{ FIM } & One level & 98.75 & 20.80 & \multirow[t]{4}{*}{3.47} & \multirow[t]{4}{*}{0.026} \\
\hline & Two level & 84.90 & 14.43 & & \\
\hline & Three level & 67.67 & 33.08 & & \\
\hline & Four level & 77.00 & 30.52 & & \\
\hline
\end{tabular}

Abbreviations: FIM, Functional Independence Measure; mJOA, modified Japanese Orthopedic Association; SD, standard deviation.

Assessment of Signal Changes, FA Values, and Surgical Outcome

Correlation between the number of levels of disease and preoperative clinical status: With the increase in level of involvement of disease there is decrease in mJOA and Functional Independence Measure (FIM) scores and increase in Neck Disability Index (NDI) and Nurick grade which reflects the poor functional status in accordance with other studies.

Correlation between Preoperative Clinical Status and MR Signal Intensity Changes

Yukawa et $\mathrm{al}^{21}$ stated that $\mathrm{T} 2 \mathrm{~W}$ signal intensity changes represent reversible pathological changes to the intramedullary cord, whereas $\mathrm{T} 1 \mathrm{~W}$ changes represent irreversible damage to the cord. Uchida et $\mathrm{al}^{22}$ proposed that signal intensity changes are signs of chronic cord damage (-Table 4 ).

\section{Correlation between Preoperative Clinical Status and DTI Metrics}

DTI values particularly FA has a strong correlation with clinical parameters like mJOA, Nurick scale, etc. In our study, it was observed that patients with FA $<0.5$ had higher grade of Nurick, that is, grade 5 in $4.3 \%$, grade 4 in $65.2 \%$, and grade 3 in $27.1 \%$ compared with grade 5 in $0 \%$, grade 4 in $23.5 \%$, and grade 3 in $47.1 \%$ in FA $>0.5$. There was a statistically significant relation observed between $\mathrm{FA}<0.5$ and higher Nurick grade in preoperative period ( $p<0.05$ ). There was a significant increase in number of patients with lesser Nurick grade in patients with FA $>0.5$ in the postoperative period than when compared with preoperative period ( $p<0.05$ ). In the group of FA $>0.5$ the mean NDI decreased to 36.8 in the postoperative period compared with the preoperative period which was 54.9. In the FA group $<0.5$, the preoperative mean NDI was 45 and then it decreased in the postoperative period which was 30.43 , but this decrease was not statistically significant $(p>$ 0.05) (-Table 5). In the group of FA $>0.5$, the preoperative mean FIM score was 94 and the postoperative mean FIM score was 100 compared with 79 and 92 in the pre- and postoperative period, respectively, in the $\mathrm{FA}<0.5$ group. But this was not statistically significant ( - Table $\mathbf{5}$ ).

\section{Correlation between Clinical Outcome and MR Signal Intensity Changes}

Mean mJOA score in the preoperative period was 10.48 and mean score in the postoperative period was 12.80 and the increase was not statistically significant. Recovery rate was calculated by using pre- and postoperative mJOA values (-Table 6).

\section{Hirabayashi method ${ }^{23}$ : Recovery rate}

$$
\frac{\text { Postop JOA-preopJOA }}{17 \text {-preop JOA }} \times 100 \%
$$

Recent study-reported clinical results were divided into four groups as follows: $75 \%$ or higher (excellent), 50 to $74 \%$ (good), 25 to $49 \%$ (fair), and less than $25 \%$ (poor). ${ }^{24}$ Therefore, we defined a poor clinical outcome as a recovery rate less than $50 \%$ in this study.

Recovery rate $>50 \%=$ good outcome

Recovery rate $\leq 50 \%=$ poor outcome

Mean $m J O A$ recovery ratio ${ }^{25}$ in the study population was observed to be $46.66 \pm 29$.19. Mean mJOA recovery ratio in patients with grade II changes was 46.49 compared with 45 in patients with grade III changes. This is in accordance with various studies. 
Table 6 Correlation of mJOA recovery ratio with demographic and radiological findings

\begin{tabular}{|l|l|l|l|}
\hline & mJOA recovery ratio & $p$-Value & $t$-Value \\
\hline $\begin{array}{l}\text { Age } 40 \text { years } \\
>40 \text { years }\end{array}$ & $66.67 \pm 28.86$ & 0.222 & 1.24 \\
\hline Grade II MRI findings & $45.04 \pm 29$ & & 0.164 \\
\hline Grade III MRI findings & $46.49 \pm 29.96$ & 0.871 & 0.962 \\
\hline FA value $<0.5$ & $45 \pm 46.62$ & 0.342 & 2.128 \\
$>0.5$ & $38.78 \pm 30.12$ & 0.04 & \\
\hline
\end{tabular}

Abbreviations: FA, fractional anisotropy; mJOA, modified Japanese Orthopedic Association; MRI, magnetic resonance imaging.

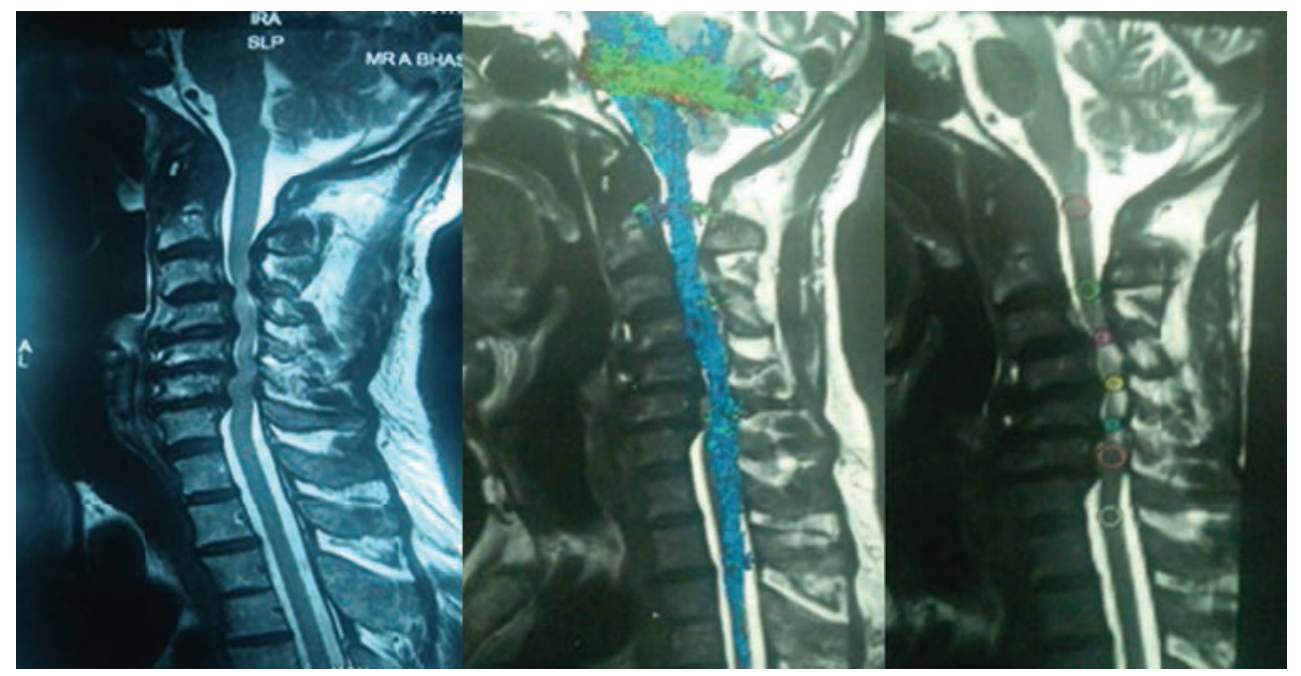

Fig. 2 A case having multiple level disco-ligamentous compression with intense hyperintensity at C3-C4, C4-C5, C5-C6, and C7 levels on T2 sequence, for which diffusion tensor imaging (DTI) has been done and region of interest (ROI) has been marked at various levels and fractional anisotropy (FA) mapping has been done.

\section{Correlation between Clinical Outcome and DTI Metrics} In our study, the mean mJOA recovery ratio in the group FA $>0.5$ was 57.32 whereas it was 38.78 in $\mathrm{FA} \leq 0.5$. So, here it is evident that the recovery ratio is better in FA $>0.5$ and it is statistically significant. Various studies show similar findings.

Wen et $\mathrm{l}^{15}$ showed that patients with a high preoperative FA value were likely to achieve better functional recovery after surgery. Dong et $\mathrm{al}^{26}$ studied FA values in 50 normal patients and 60 patients with CSM and he correlated preoperative and postoperative mJOA score and Nurick grades with DTI parameters, and found that the FA value was positively correlated with the mJOA score but negatively correlated with the Nurick grade.

Vedantam et $\mathrm{al}^{27}$ found that FA at the level of maximal compression correlated positively with preoperative mJOA score. Preoperative FA correlated inversely with recovery throughout the postoperative period. This was statistically significant at 12-month postsurgery and nearly so at 6 and 24 months. Patients with preoperative FA $<0.55$ had a statistically significant difference in outcome compared with FA $>0.55$. They concluded that FA is an objective measure of function and could provide a basis for prognosis. FA is particularly useful if preoperative values are less than 0.55 .

\section{Conclusion}

In our study, we found that patients below 40 years of age had better functional outcome after surgery. Functional status is inversely related to the increasing levels of involvement of the disease. Patients with preoperative Nurick grade $<2$ had better surgical outcome. Signal intensity changes on both T1W and T2W carries poor prognosis. FA can be a potential quantitative tool to predict the functional outcome following decompressive surgery for degenerative cervical myelopathy conditions, in particular lower FA values carries poor prognosis.

\section{Authors' contributions}

All authors were involved in the conceptualization, collection of data, DTI FA value calculation, surgery, and follow-up evaluation.

Funding

None. 


\section{Conflict of interest}

None declared.

\section{References}

1 Epstein N. Ossification of the cervical posterior longitudinal ligament: a review. Neurosurg Focus 2002;13(02):ECP1

2 Fernández de Rota JJ, Meschian S, Fernández de Rota A, Urbano V, Baron M. Cervical spondylotic myelopathy due to chronic compression: the role of signal intensity changes in magnetic resonance images. J Neurosurg Spine 2007;6(01):17-22

3 Baron EM, Young WF. Cervical spondylotic myelopathy: a brief review of its pathophysiology, clinical course, and diagnosis. Neurosurgery 2007;60(1, Supp1 1)S35-S41

4 Henderson FC Sr, Austin C, Benzel E, et al. Neurological and spinal manifestations of the Ehlers-Danlos syndromes. Am J Med Genet C Semin Med Genet 2017;175(01):195-211

5 Boden SD, McCowin PR, Davis DO, Dina TS, Mark AS, Wiesel S. Abnormal magnetic-resonance scans of the cervical spine in asymptomatic subjects. A prospective investigation. J Bone Joint Surg Am 1990;72(08):1178-1184

6 Kang Y, Lee JW, Koh YH, et al. New MRI grading system for the cervical canal stenosis. AJR Am J Roentgenol 2011;197(01):W134-40

7 Lyu RK, Tang LM, Chen CJ, Chen CM, Chang HS, Wu YR. The use of evoked potentials for clinical correlation and surgical outcome in cervical spondylotic myelopathy with intramedullary high signal intensity on MRI. J Neurol Neurosurg Psychiatry 2004;75(02):256-261

8 Matsuda Y, Miyazaki K, Tada K, et al. Increased MR signal intensity due to cervical myelopathy. Analysis of 29 surgical cases. J Neurosurg 1991;74(06):887-892

9 Demir A, Ries M, Moonen CT, et al. Diffusion-weighted MR imaging with apparent diffusion coefficient and apparent diffusion tensor maps in cervical spondylotic myelopathy. Radiology 2003;229(01):37-43

10 Jellison BJ, Field AS, Medow J, Lazar M, Salamat MS, Alexander AL. Diffusion tensor imaging of cerebral white matter: a pictorial review of physics, fiber tract anatomy, and tumor imaging patterns. AJNR Am J Neuroradiol 2004;25(03):356-369

11 Kang M, Anderer E, Elliott R, Kalhorn S, Cooper P, Frempong-Boadu A. Diffusion tensor imaging of the spondylotic cervical spinal cord: a preliminary study of quantifiable markers in the evaluation for surgical decompression. Int J Head Neck Surg 2011;5:01

12 Mamata H, Jolesz FA, Maier SE. Apparent diffusion coefficient and fractional anisotropy in spinal cord: age and cervical spondylosisrelated changes. J Magn Reson Imaging 2005;22(01):38-43

13 Budzik JF, Balbi V, Le Thuc V, Duhamel A, Assaker R, Cotten A. Diffusion tensor imaging and fibre tracking in cervical spondylotic myelopathy. Eur Radiol 2011;21(02):426-433
14 Kara B, Celik A, Karadereler S, et al. The role of DTI in early detection of cervical spondylotic myelopathy: a preliminary study with 3-T MRI. Neuroradiology 2011;53(08):609-616

15 Wen CY, Cui JL, Liu HS, et al. Is diffusion anisotropy a biomarker for disease severity and surgical prognosis of cervical spondylotic myelopathy? Radiology 2014;270(01):197-204

16 Aota Y, Niwa T, Uesugi M, Yamashita T, Inoue T, Saito T. The correlation of diffusion-weighted magnetic resonance imaging in cervical compression myelopathy with neurologic and radiologic severity. Spine 2008;33(07):814-820

17 Crandall PH, Batzdorf U. Cervical spondylotic myelopathy. J Neurosurg 1966;25(01):57-66

18 Naderi S, Özgen S, Pamir MN, Özek MM, Erzen C. Cervical spondylotic myelopathy: surgical results and factors affecting prognosis. Neurosurgery 1998;43(01):43-49, discussion 49-50

19 Matz PG, Anderson PA, Holly LT, et al. Joint Section on Disorders of the Spine and Peripheral Nerves of the American Association of Neurological Surgeons and Congress of Neurological Surgeons. The natural history of cervical spondylotic myelopathy. J Neurosurg Spine 2009;11(02):104-111

20 Fujiwara K, Yonenobu K, Ebara S, Yamashita K, Ono K. The prognosis of surgery for cervical compression myelopathy. An analysis of the factors involved. J Bone Joint Surg Br 1989;71(03): 393-398

21 Yukawa Y, Kato F, Yoshihara H, Yanase M, Ito K. MR T2 image classification in cervical compression myelopathy: predictor of surgical outcomes. Spine 2007;32(15):1675-1678, discussion 1679

22 Uchida K, Nakajima H, Sato R, et al. Multivariate analysis of the neurological outcome of surgery for cervical compressive myelopathy. J Orthop Sci 2005;10(06):564-573

23 Hirabayashi K, Miyakawa J, Satomi K, Maruyama T, Wakano K. Operative results and postoperative progression of ossification among patients with ossification of cervical posterior longitudinal ligament. Spine 1981;6(04):354-364

24 Maki S, Koda M, Kitamura M, et al. Diffusion tensor imaging can predict surgical outcomes of patients with cervical compression myelopathy. Eur Spine J 2017;26(09):2459-2466

25 Karpova A, Arun R, Davis AM, et al. Predictors of surgical outcome in cervical spondylotic myelopathy. Spine 2013;38(05):392-400

26 Dong F, Wu Y, Song P, et al. A preliminary study of 3.0-T magnetic resonance diffusion tensor imaging in cervical spondylotic myelopathy. Eur Spine J 2018;27(08):1839-1845

27 Vedantam A, Rao A, Kurpad SN, et al. Diffusion tensor imaging correlates with short-term myelopathy outcome in patients with cervical spondylotic myelopathy. World Neurosurg 2017; 97:489-494 